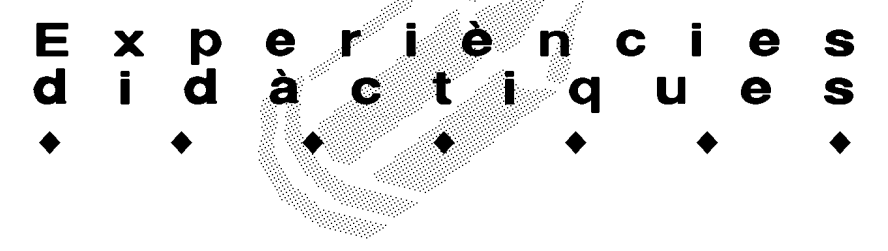

\title{
UN PLA ESTRATÈGIC PER A LA RECERCA EDUCATIVA: L'ATENCIÓ A LA DIVERSITAT I LA UTILITZACIÓ DE LES TIC
}

\author{
Pere Gatell Artigas, M. Rosa Graners Clapers, Joan Pascual Mallada i Rosa Olivé Ollé. CEIP Eladi Homs. Valls
}

\section{Introducció}

Resumir en poques paraules vint anys de treball d'una escola és complicat, i més tractant-se del CEIP Eladi Homs de Valls, que durant molts anys ha sigut CERE d'integració d'alumnes amb NEE i actualment és una escola d'una línia amb quatre USEE.

En els quatre últims anys l'escola, per continuar en la línia iniciada en el CERE d'atenció a la diversitat, va decidir proposar un pla estratègic que permetés seguir treballant activament i oficialitzar maneres anteriors de treballar reflectides en la seva organització escolar, curricular, metodològica i en els plans d'avaluació de centre.

Cada projecte neix com a resultat d'una sèrie d'esdeveniments, assessoraments $\mathrm{i}$ experiències que es van recollint al llarg del temps.

Després que l'escola deixés de ser un centre experimental (CERE, experiència portada a terme durant més de deu anys), d'un seguit d'assessoraments de llengua oral, de lectoescriptura i de la incorporació a les TIC com a competència bàsica, sorgeix aquest pla estratègic, orientat a treballar en activitats de comunicació (llenguatge corporal, oral, i escrit) fent ús de les tecnologies de la informació i comunicació de forma inclusiva amb tots els alumnes de l'escola (ordinaris, integrats a l'aula ordinària i de NEE).

Aquest pla estratègic s'ha desenvolupat tenint en compte la realitat del centre a nivell pedagògic $i$ organitzatiu, que es concreta en quatre punts:

1. En el PEC: on dos dels cinc trets d'identitat com a escola pública són diversitat i integració (inclusió), desenvolupant àmpliament els apartats d'organització escolar, metodologia, criteris de flexibilització i avaluació.

2. En el PCC: I'hem desenvolupat posant especial interès que sigui únic, ampli $\mathrm{i}$ donant resposta a tots els alumnes de l'escola.

3. En els plans anuals de centre i el pla d'avaluació interna: planificant curs a curs organitzacions, horaris i activitats que possibilitin la participació de tots els alumnes.

4. En les programacions de classe $i$ en les ACIS: fent possible un treball adequat a les NEE de l'alumne integrat en una aula.
És a partir d'aquesta realitat que hem orientat el treball, en el camp de les TIC i la comunicació, a través d'activitats on la inclusió de tots els alumnes de l'escola és una realitat i on la interrelació de totes les propostes didàctiques determinen un treball de col-laboració entre tots els professionals de l'escola. Això possibilita una immersió en els diferents elements que configuren la comunicació i la utilització de les noves tecnologies en les diferents àrees i en la vida quotidiana.

\section{Objectius}

Si som capaços d'ampliar el mateix concepte que ens suggereix el terme "comunicació", crearem el context adequat on tots els interlocutors tindran capacitat per expressar-se.

L'heterogeneïtat d'alumnes (també els que presenten necessitats educatives i necessitats educatives especials) ens ha portat a buscar constantment recursos per afavorir l'aprenentatge de la llengua parlada i escrita. Un cop més, l'ús dels sistemes de comunicació augmentativa permet a tots els alumnes poder aprofundir en diversos coneixements:

- Tenir competència comunicativa plena en el llenguatge oral com a mitjà de realització personal $\mathrm{i}$ social, com a base de la fixació del pensament i com a punt de referència per a l'adquisició i enriquiment del llenguatge escrit.

- Comprendre i expressar-se amb adequació al mitjà oral o escrit, al tipus de missatge i a les necessitats escolars i socials de l'edat.

- Assegurar el lèxic fonamental i ampliar-lo i enriquirlo en la mesura que es diversifiquen els seus coneixements $i$ els seus àmbits d'expressió personal.

- Observar el funcionament de la llengua tant per organitzar la seva expressió, segons la seqüència lògica de les idees, com per adonar-se de totes les possibilitats expressives i lúdiques del llenguatge.

- Expressar-se per escrit utilitzant tècniques diverses (descripció, diàleg, carta...) amb finalitats també diverses ( fabulació, simulació de situacions comunicatives, expressió de vivències...). 


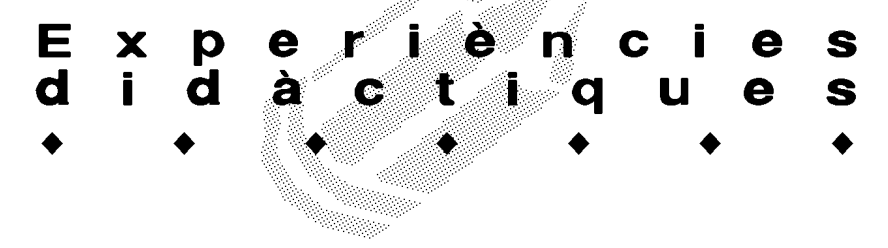

- Conèixer i acceptar el propi cos, com també les seves possibilitats de moviment.

- Identificar i utilitzar formes de comunicació expressives corporals, tot desenvolupant el sentit estètic i creatiu.

- Accedir al comportament social que faciliti el creixement individual mitjançant la participació solidària, la responsabilitat i el respecte a les altres persones, especialment la utilització de les relacions de cooperació indispensables en una activitat física col-lectiva.

- Explorar el potencial de les TIC en totes les àrees i àmbits de l'ensenyament i l'aprenentatge.

- Utilitzar les TIC per donar suport a objectius educatius generals, com ara desenvolupar actituds per a l'aprenentatge, millorar la presentació dels treballs, les actituds inquisitives de recerca i de resolució de problemes, aprendre col-laborativament i treballar en equip.

- Aprofitar els nous entorns de comunicació per participar en comunitats d'aprenentatge formals i informals.

La responsabilitat d'afavorir l'adquisició de l'habilitat de comunicació continua sent de les persones que envolten l'infant. Sovint aquestes persones hauran d'aprendre, en grau més o menys elevat, unes habilitats que normalment no utilitzen en la comunicació parlada $\mathrm{i}$ que, per tant, són atípiques. Això vol dir que no es pot esperar que sempre apareguin espontàniament, sovint han de ser ensenyades, no sols a l'infant sinó també a la família i als professionals.

Tots aquests objectius s'han concretat en:

- Activitats d'expressió oral.

- Activitats d'expressió corporal.

- Activitats d'expressió escrita.

- Ús de les TIC (Tecnologies d'Informació i Comunicació).

- Activitats d'atenció a la diversitat: adaptacions.

\section{Actuacions realitzades per cicles en l'àmbit de co- municació}

En l'apartat de comunicació han estat bàsicament implicades les àrees d'educació física i les àrees de llengua. Per a cada activitat s'ha desenvolupat en tots el cicles i cursos una unitat didàctica que ens ha permès observar una verticalització de tot el procés d'expressió oral i corporal.

\section{Educació Infantil}

Dins de l'àrea de llengua (català) s'han treballat rutines comunicatives, les onomatopeies, els jocs i les danses populars, la memorització de dites i poemes i l'escenificació de contes amb la intenció d'apropar el nen a l'àmbit expressiu, on el cos i la veu es configuren com a eines de comunicació.

Activitats realitzades: Hem treballat "el bon dia", els dies de la setmana, salutacions amb el cos, onomatopeies d'animals, sorolls de coses de casa i de màquines, sons ambientals del carrer, el joc de les cadires, joc de les estàtues, "ja ve la primavera", "la ginesta" i "La rateta que escombrava l'escaleta "...

\section{Cicle inicial}

Dins de l'àrea d'EF s'ha treballat la identificació i producció de formes de transmetre els sentiments (expressió facial i corporal) i la dramatització, on els jocs dramàtics i les dramatitzacions de contes i situacions de la vida quotidiana han apropat els alumnes a una realitat comunicativa lligada a la realitat integral de la persona.

Paral-lelament s'ha fet un treball dins de l'àrea de llengua on la lectura d'imatges, la verbalització d'un conte, la creació i utilització de frases que transmetin sentiments i sensacions han fonamentat el llenguatge oral.

Totes aquestes experiències comunicatives han tingut, però, una tercera via d'expressió, que és el llenguatge escrit i plàstic, on s'han reflectit a través de l'escriptura i les imatges experiències personals, utilitzant les TIC con a eina de treball.

Activitats realitzades: Hem treballat jocs de lateralitat, exercicis d'entonació, exercicis de lectura, enregistrament en casset de les corresponents lectures, memorització de textos, treball de rodolins i escenificació de contes ("El Tabalet"...).

\section{Cicle mitjà}

Com a continuació del procés encetat en anteriors cicles, als alumnes se'ls ha anat oferint la possibilitat d'experimentar dins de l'àrea d' EF amb elements més complexos, com llegendes, petits textos teatrals i la utilització d'objectes com a elements de suport en la comunicació i la creació.

Això ha permès dins de l'àrea de llengua el treball en la identificació de diferents tipologies textuals, verbalitzant en forma de narració oral, dites, frases fetes, rodolins, poemes, assemblees de classe... Aquesta verbalització s'ha plantejat a través de diferents mitjans: el teatre, els enregistraments de ràdio, els enregistraments de vídeo...

En relació amb el llenguatge escrit ens ha permès una identificació clara de les diferents tipologies textuals: la descripció, el diàleg, la narració, la poesia, la carta, les instruccions...

Activitats realitzades: Hem treballat endevinalles, descripcions a nivell oral, poemes, memorització de textos, exercicis corporals, jocs dramàtics ("La llegenda de la Pera"....). 


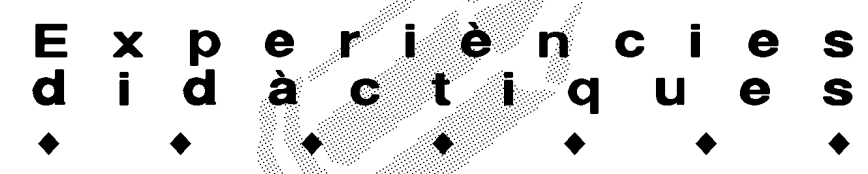

\section{Cicle superior}

Dins del procés de control dels diferents llenguatges que ens permeten comunicar-nos, i com a resultat dels treballs previs al llarg dels diferents cicles de primària $i$ dins del cicle superior, hem aprofundit els codis que sustenten els diferents llenguatges: llenguatge teatral, llenguatge escrit i oral, llenguatge plàstic i visual, introduint nous elements com ara el còmic, la publicitat, l'entrevista, els diferents tipus de teatre, la notícia...

Activitats realitzades: Hem treballat lectura dramatitzada de textos, memorització de textos, jocs dramàtics, improvisacions, creació de textos teatrals a partir d'improvisacions i el muntatge teatral: poemes, entrevistes, obres de teatre ("La flor del lliri blau", "On sóc?"...).

Aquestes activitats queden reflectides en diversos moments al llarg del curs, on es donen a conèixer a la comunitat educativa: pares, mestres, alumnes: Sant Jordi, setmana cultural i festa final de curs.

\section{Actuacions realitzades per treballar les TIC}

Per tal de dur a terme les activitats en TIC els mestres han rebut un curs de TIC-1. Aquesta ha estat una formació genèrica i personal en relació amb les necessitats del mestre i de l'alumnat, desenvolupant programes i mitjans específics segons els casos.

Paral.lelament alguns professionals del centre han participar en els SATI, SNDEE, SAIP per aprofundir-hi més.

Paral.lel a aquest treball de formació hem continuat desenvolupant activitats en les diferents àrees utilitzant els programes següents: Text: Word 97/Parlador/ Adaptacions Word. Gràfics: Kid-Pix / Paint / Paint Shop Pro/ ACD.See. Programes educatius: Clics. CD Rom educatius, calculadora parlant, Galí... Multimèdia i Comunicació: Contes amb SPC, Power Point. Internet: Edu 365. Webs de contes, pàgines web, e-mail.

Hem elaborat acords de Claustre per verticalitzar l'ús del processador de text i de dibuix i avaluar-los.

Tot el treball d'ús d'eines informàtiques s'ha anat articulant en funció de l'àrea i la dotació tècnica disponible, que s'ha anat ampliant al llarg d'aquests quatre anys.

\section{Actuacions realitzades en relació amb l'atenció a la diversitat}

En comunicació:

- Llenguatge augmentatiu (pictogràfic, gestual...).

- Plafons de comunicació.

- Suport de les TIC tant en el llenguatge oral com en el llenguatge escrit (parlador, adaptacions Word).

- Adaptacions segons la dificultat en la producció de sons.

- Adaptacions de la llargada del text (quantitat).

En l'ús de les tecnologies de la informació i la comunicació:

- Els alumnes amb NEE han utilitzat els mateixos programes que la resta d'alumnes, però amb les adaptacions necessàries per facilitar-los els procediments d'ús. Per exemple, adaptacions Word, el parlador...

- Els mestres han utilitzat els següents recursos per preparar les activitats dels alumnes: Utilització de pictogrames; adaptació del text en format informàtic: adaptacions dels llibres de text de paper a "format informàtic", adaptacions del tipus de lletra i grandària...; adaptació de les activitats.

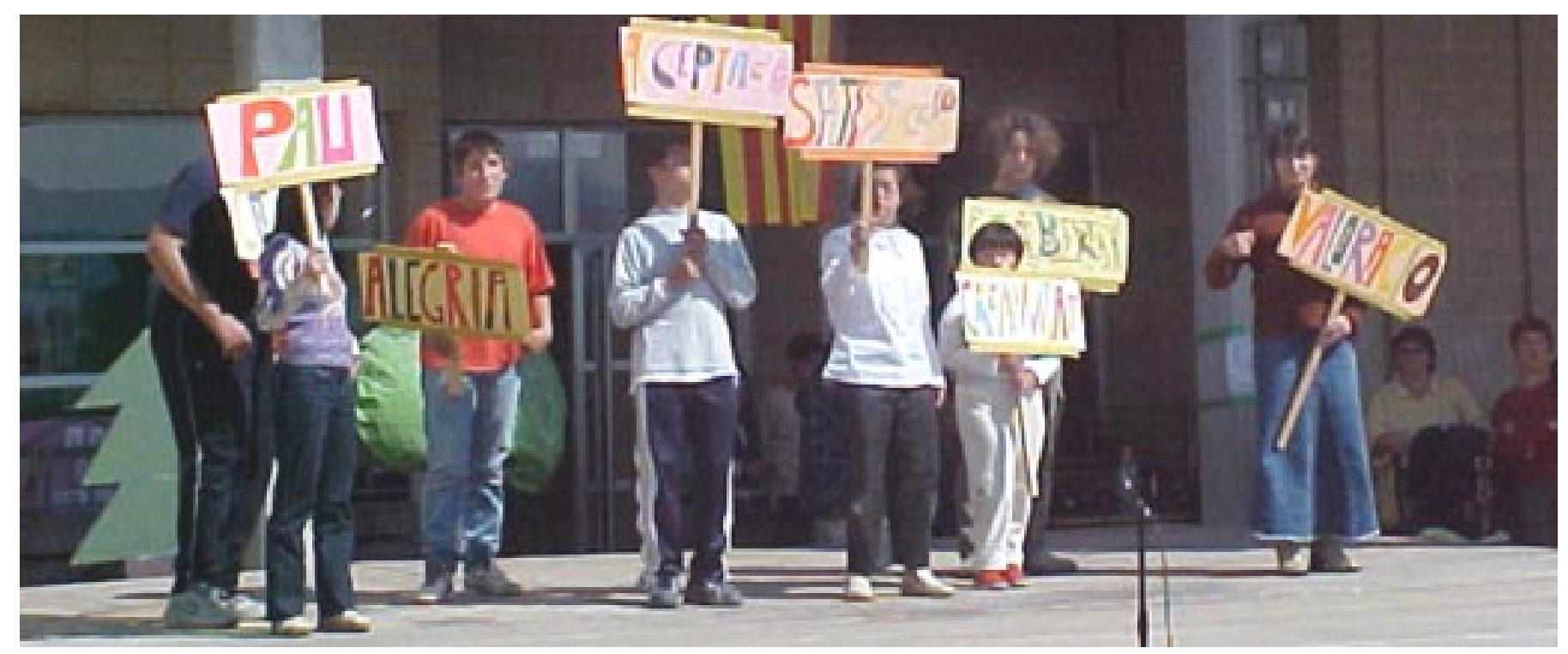




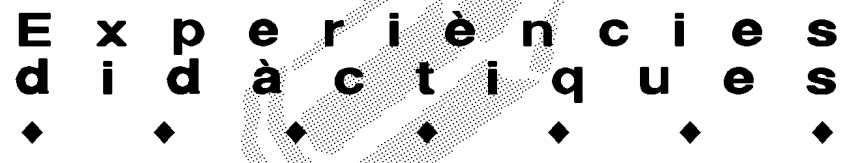

\section{Organització}

El pla estratègic s'ha desenvolupat amb la implicació de tot el professorat del centre i pensat perquè hi participi la diversitat de l'alumnat (NEE).

Per poder treballar de manera gradual totes aquestes actuacions pedagògiques dins del pla estratègic, les programacions de classe contemplen les activitats de comunicació i de lesTIC.

\section{Conclusions}

- S'han concretat i verticalitzat activitats d'expressió oral en tots els cicles.

- S'han desenvolupat els aspectes d'expressió oral en l'àrea de llengua i expressió corporal en l'àrea d' EF de forma interdisciplinària.

- S'ha concretar i verticalitzat l'ús de les TIC en tots els cicles, partint del desenvolupament de cada àrea.

- S'ha implicat tot el Claustre i alumnat en les activitats de comunicació i TIC.

- S'ha ampliat l'equipament informàtic en un ordinador per aula i una aula d'ordinadors. Cablejat de tota l'escola.

- Hem rebut una formació bàsica en l'ús de les TIC per a tot el professorat.

- Hem adaptat materials a través de l'ús de les TIC.

- S'han revisat i contextualitzat les competències bàsiques de les TIC.

- Hem acordat criteris d'avaluació en l'expressió oral i l'ús de les TIC.

- S'han incorporat a la plantilla de l'escola amb caràcter definitiu els professors responsables d'aquest pla.

- S'han aplicat aquests acords a tots els alumnes de l'escola: aula ordinària, flexibilitzacions i USEE.

Les activitats de comunicació han permès desenvolupar l'aspecte actitudinal i social de la comunicació. Al finalitzar el procés de treball els alumnes diuen:

\section{Què hem après fent teatre?}

"He après a treballar en grup, a no tenir vergonya, a parlar fort i clar, a tenir paciència, a respectar els altres, a actuar i fer un text per a una obra de teatre". (Laia).

"Jo he après a moure'm més bé, a no tenir tanta vergonya i sobretot a vocalitzar les paraules i fer gestos mentre dic el text". (Sònia).

"He après que se me'n vagi la vergonya, a expressarme més, a parlar millor i mes alt, a estar atenta al text $\mathrm{i}$ tenir paciència". (Rocío).

"A vocalitzar, fer moviments amb el text, a tenir un to de veu més agut o greu parlant, i recitant poesia, he après a millorar el que feia". (Manuela).
"Fent teatre hem après a improvisar, a treballar en grup i a tenir paciència." (Laura).

"He après a vocalitzar més bé, a cridar més fort, a tenir més paciència, a escriure una obra de teatre $\mathrm{i} a$ representar una obra de teatre" (Marc).

"A treballar amb els companys, a fer resums a partir d'una història, a representar un text o un poema, a expressar-me amb el cos, a treure'm la vergonya". (Míriam).

"Fent teatre he après a tenir paciència mentre veus com els teus companys actuen, a cridar més quan parles, a fer gestos i a moure't per l'espai, etc. Hem transformat un llibre en una obra de teatre". (Eva).

"Fent teatre he après a no tenir vergonya actuant, a parlar fort i que s'entengui el que he de dir, i les diferents parts d'una obra de teatre". (Laura).

"He après a cridar més quan faig teatre, ara ja no tinc tanta vergonya; a treballar en grup, a respectar els companys i a tenir paciència. Hem fet l'obra de teatre i hem escrit una obra de teatre". (Mireia).

"Que hem de parlar fort, no estar quiets, fer algun moviment, no tenir vergonya a expressar, a passar-ho bé. Per fer l'obre de teatre, hem llegit el text, ens hem ajudat a representar els personatges, hem estudiat què és, de quines parts està formada. Hem treballat tots junts". (Andrea).

"Jo fent teatre he après a vocalitzar millor, a fer teatre, a parlar millor, a respectar els companys, a relacionar-me més amb ells. És una feina que hem assajat en grup perquè així m'acostumo a treballar amb els meus companys. Hem fet improvisacions, textos de teatre, hem llegit teatre i hem parlat teatre". (Alba).

"Hem après moltes coses: a escoltar els companys, a fer teatre, a parlar fort i que s'entengui bé el text, a saber esperar". (Laia).

"A expressar-me, a treballar en grup i a vocalitzar". (Naroa).

"A mi l'obra de teatre m'ha fet obrir els ulls, m'ha fet molta il-lusió fer una obra de teatre. Hem après a expressar els sentiments dels altres, hem après a no tenir vergonya al fer alguns gestos, hem après a cridar més $\mathrm{i}$ no riure quan algú fa una cosa o s'equivoca. També hem après a ajudar els altres quan no es recorden del que han de dir i també a escollir bé la roba". (Vanessa).

Aquestes propostes pedagògiques al voltant de la comunicació i l'ús de les TIC, encetades prèviament al pla estratègic i concretades en el mateix pla, s'han perfilat com una bona eina de treball a seguir desenvolupant els propers cursos. 